\title{
Representação social de pais sobre o filho prematuro na Unidade de Terapia Intensiva Neonatal
}

\author{
Social representation of fathers regarding their premature child in the Neonatal Intensive Care Unit \\ Representación social de los padres sobre el hijo prematuro en la Unidad de Terapia Intensiva Neonatal
}
Jovanka Bittencourt Leite de Carvalho', Ana Cristina Pinheiro Fernandes Araújo', Íris do Céu Clara Costa', Rosineide Santana de Brito', Nilba Lima de Souza'

'Universidade Federal do Rio Grande do Norte. Programa de Pós-Graduação do Centro de Ciências da Saúde. Natal, RN

Submissão: $04 / 05 / 2008$

Aprovação: 3 1/08/2009

\section{RESUMO}

Pesquisa Qualitativaa Que teve como objetivo conhecer a representação social do pai diante do filho prematuro. Os dados foram coletados no período de maio a junho de 2008 por meio de entrevista semi-estruturada, junto a 17 pais cujos filhos prematuros estavam internados na UTIN de duas instituições públicas de natal-RN. Os depoimentos foram tratados e analisados com base na teoria das representações sociais (TRS). Os resultados revelaram Que os pais ao estarem com seus filhos internados vivenciam emoções Que são traduzidas por medo, angústia, ansiedade, solidão e se entremeiam a fé, alegria e esperança. Para o pai a UTIN representa um ambiente assustador, mas necessário aos cuidados especializados requeridos pelas condições do recém nascido prematuro.

Descritores: Pai; Nascimento prematuro; Unidades de terapia intensiva neonatal.

\begin{abstract}
Qualitative study that aimed at understanding the social representation of a parent with a premature child. The data were collected between May and June 2008, in a semi-structured interview with 17 parents whose premature children were hospitalized in the NICU of two public institutions in Natal, Brazil. The reports were analyzed based on the Social Representations Theory (SRT). The results reveal that the hospitalization of their children causes parents to experience emotions of fear, anguish, anxiety, loneliness interspersed with those of faith, joy and hope. For a parent the NICU is a frightening environment, albeit necessary for the specialized care that the conditions of the premature newborn require.
\end{abstract}

Descriptors: Fathers; Premature birth, Intensive care units neonatal.

\section{RESUMEN}

Investigación cualitativa tiene como objetivo conocer la representación social del padre frente del hijo prematuro. Los datos fueron tomados en el periodo de mayo a junio de 2008 mediante entrevista semi-estructurada a 17 padres con hijos prematuros internados en la UTIN de dos instituciones públicas de Natal-RN. Las declaraciones fueron tratadas y analizadas con base en la teoría de las representaciones sociales (TRS). Los resultados revelaron Que los padres al acompañar a sus hijos internados viven emociones Que se traducen en miedo, angustia, ansiedad, soledad y se entreveran con fe, alegría y esperanza. Para el padre la UTIN representa un ambiente amedrentador, pero necesario.

Descriptores: Padre; Nascimento prematuro; Unidades de terapia intensiva neonatal. 


\section{INTRODUÇÃO}

A gravidez e o parto são momentos de expectativas e ansiedades tanto para a mulher como para o homem. São períodos de mudanças e resolutividade Que, embora sejam consideradas fisiológicas, velam alteração da homeostase do organismo materno. Essas mudanças, dependendo do grau de desequilíbrio, desencadeiam uma gestação de risco.

A gestação de risco é conceituada como agravos Que ocorrem durante o período gestatório com evolução desfavorável tanto para a mãe Quanto para o feto, no Qual a vida ou saúde de ambos pode ser atingida ${ }^{(1)}$. Em meio aos fatores Que desencadeiam uma gravidez de risco a hipertensão arterial assume lugar de destaque.

Estudo desenvolvido no Canadá revelou Que a grávida com hipertensão tem duas vezes maior probabilidade de partos prematuros, e Quando associado à proteinúria esse valor é Quadruplicado $^{(2)}$. No Brasil, as síndromes hipertensivas da gestação, tanto a hipertensão arterial crônica Quanto a hipertensão gestacional, aumentam o risco para o desfecho perinatal desfavorável Quais sejam: apgar baixo no primeiro e Quinto minuto, infecção neonatal, síndrome da angústia respiratória, recém nascido pequeno para a idade gestacional e prematuridade ${ }^{(3)}$. Estima-se também que anualmente em todo mundo nascem 20 milhões de recém nascidos com baixo peso, muitos em conseqüência de partos prematuros ${ }^{(4)}$.

A prematuridade é definida pela Organização Mundial da Saúde como nascimentos Que ocorrem antes do termo, ou seja, com idade gestacional inferior a 37 semanas de gestação e peso fetal menor de 2500 gramos $^{(5)}$

Nas Américas, aproximadamente 12\% do total de neonatos, ou seja, 1.944.852 recém-nascidos têm peso inferior a 2.500 gramos, e 6\% nascem antes de completar 37 semanas de gestação. $O$ baixo peso ao nascer é o mais importante de todos os fatores da mortalidade neonatal ${ }^{(5)}$. No Brasil no ano de 2006, a prevalência de recém-nascidos prematuros variou de 5 a $11 \%$ e no Rio Grande do Norte foi de $7,7 \%{ }^{(6)}$.

Isto nos conduz à concepção de Que a prematuridade proveniente de uma gestação de risco leva os pais a situações adversas ao seu cotidiano. Dessa forma, os cuidados prestados ao recém nascido prematuro, internado em uma unidade de terapia intensiva neonatal (UTIN), devem contemplar estratégias assistenciais tanto para a mãe como para o pai. Entendemos que o prematuro diante de suas características somadas às necessidades de cuidados intensivos assume várias representações para os pais. Entretanto, neste estudo será abordado o genitor no contexto da prematuridade e da UTIN. Assim sendo, concebemos ser necessário conhecer a representação social do pai diante do filho prematuro internado na UTIN, mediante a pressuposição de Que ter um filho prematuro desencadeia no pai diferentes sentimentos Que dificultam a sua atitude junto ao recém nascido.

No contexto da parturição, estudos afirmam Que o companheiro Quando participa, e está envolvido emocionalmente com o bem estar da mulher e do filho pode ser muito útil no cuidado de ambos. O pai é o primeiro a acompanhar e cuidar de seu bebê na UTIN. É ele Quem mantém os primeiros contatos com a equipe de saúde, cuida da companheira fragilizada, além de assumir outras atividades domésticas e profissionais ${ }^{(7,8)}$.

Tratando-se do parto prematuro, esse pode representar para o homem uma ameaça Quanto à segurança e à concretude da gestação dentro do paradigma de normalidade, levando-o a vivenciar sentimentos de natureza diversas tais como o medo, preocupação e anseios dentre outros ${ }^{(9)}$.

Diante disso surge o seguinte Questionamento - O Que representa para o pai ter um filho prematuro e internado na UTIN?

Acreditamos Que o alcance desse objetivo contribuirá para o preenchimento de lacunas existentes sobre a vivência do pai no âmbito do nascimento sobretudo prematuro.

\section{MÉTODO}

\section{Tipo de estudo}

Trata-se de uma pesquisa de abordagem Qualitativa baseada na Teoria das Representações Sociais, desenvolvida em duas maternidades públicas de Natal-RN Que possuem UTIN e adotam os princípios da humanização da assistência. O estudo foi realizado no período de maio a agosto de 2008.

\section{Participantes da Pesquisa}

Participaram da investigação 17 homens Que estavam com seus filhos prematuros internados na UTIN, cujas companheiras vivenciaram uma gestação de alto risco. A inclusão dos participantes ocorreu da seguinte maneira: entramos em contato com os pais Que se encontravam com seus bebês internados com mais de 48 horas na UTIN cujas mães foram acometidas de hipertensão arterial durante a gestação. Optamos por esse espaço de tempo por considerarmos Que após essas horas críticas e instáveis, para o recém nascido e família, os pais teriam um melhor entendimento da situação vivenciada e assim poderiam falar da sua experiência com mais tranqüilidade. Quanto à decisão de ter a hipertensão como um dos critérios de inclusão do participante no estudo foi por entendermos Que além dessa patologia na gravidez assumir lugar de destaque, teríamos possível similaridade entre as causas do nascimento prematuro. $\mathrm{Na}$ ocasião da entrevista, explicamos aos pais os objetivos e finalidade da investigação indagando sobre a possibilidade de sua participação na investigação.

Após os esclarecimentos prévios, todos os pais abordados concordaram em participar do estudo e assinaram o termo de consentimento livre e esclarecido atendendo às exigências da Resolução 196/96, do Conselho Nacional de Saúde no Que se refere à pesquisa com seres humanos ${ }^{(10)}$.

Para a coleta de dados, utilizamos um roteiro de entrevista contendo variáveis demográficas relativas à idade, situação conjugal, renda familiar, escolaridade e profissão a fim de caracterizar os participantes do estudo e uma Questão norteadora - O Que representa para o senhor ter um filho internado na UTIN. Antecedeu essa etapa, a aprovação da investigação enQuanto projeto pelo Comitê de Ética em Pesquisa da Universidade Federal do Rio Grande do Norte (CEP-UFRN) segundo protocolo no 81/07, autorização formal das instituições envolvidas e do pai a ser entrevistado.

As entrevistas foram gravadas mediante a aprovação dos participantes no intuito de apreender os depoimentos na íntegra. A etapa seguinte foi constituída pela transcrição dos mesmos o mais breve possível, para não perdermos as informações e observações coletadas e vivenciadas por nós durante a entrevista. Salientamos Que estivemos atentas a todas reações, atitudes e 
expressões apresentadas pelos entrevistados durante os depoimentos. Todas as manifestações dos pais, no decorrer dessa fase, foram registradas no diário de campo com vistas a contribuir na análise das falas.

Para o tratamento dos dados, utilizamos os procedimentos do método de análise de conteúdo na modalidade de análise temática $^{(11)}$. Assim sendo, percorremos a etapa de pré-análise Que constituiu a transcrição dos depoimentos e leitura flutuante de modo a estabelecermos um contato com o material a ser analisado. Foram determinados os núcleos de sentido, os Quais, por um processo de recorte, agregação, codificação e categorização resultaram na seguinte temática: Sentimentos paternos diante do filho prematuro na UTIN.

Essa temática sofreu inferência, interpretações e foi analisada de conformidade com a Teoria das Representações Sociais (TRS). A construção de uma representação não se dá individualmente, "mas em grupo, elas são partilhadas por um grande número de pessoas, transmitidas de uma geração à seguinte e imposta a cada um de nós sem o nosso consentimento consciente"(12).

Dessa forma, optamos por essa teoria como base para análise dos depoimentos dos pais, julgando-a como adequada aos propósitos da investigação.

\section{RESULTADOS E DISCUSSÃO}

\section{Características dos Participantes}

Participaram do estudo dezessete homens aos Quais atribuímos nomes fictícios como forma de melhor nos referirmos aos mesmos. A idade dos participantes variou entre 19 e 50 anos predominando a faixa etária de 25 a 29 anos. A maioria afirmou ter renda familiar entre I a 3 salários mínimos (76,46\%) e escolaridade variando do ensino médio incompleto até nível superior. Os maiores predomínios foram nas classes - ensino médio incompleto $(41,17 \%)$ e ensino médio completo $(35,29)$. Quanto à situação conjugal todos conviviam com a mulher sob o mesmo teto.

De acordo com as respostas dos pais, diversas profissões foram apontadas, tais como: agricultor, segurança, gari, auxiliar de pedreiro, pedreiro, técnico de enfermagem, capoteiro, marceneiro, auxiliar de mecânica, montador e militar.

\section{Sentimentos paternos diante do filho prematuro na UTI- Neonatal}

A UTIN por ser um ambiente Que indica agravamentos das condições de saúde do neonato desencadeia em seus familiares emoções de diferentes naturezas. Tratando-se dos entrevistados deste estudo, vários sentimentos foram apontados por eles.

Os pais afirmaram Que ter um filho prematuro em uma UTIN representa para eles insegurança dada a fragilidade do recém nascido e a possibilidade do mesmo não sobreviver. Sentimentos de medo, tristeza, angústia e impotência diante da situação vivenciada podem ser observados nos discursos a seguir:

"Eu tenho muito medo dela estar ai na UTI porque ela é muito pequenininha, tenho medo dela não se criar, de perdermos ela". (Thiago)

"É muito triste ver meu filho na UTI cheio de fios, tubos. Sem saber o que vai acontecer com ele, será que ele vai ficar com problemas. Eu fico muito triste, preocupado da uma angústia danada. A gente fica muito inseguro, frágil e sozinho diante dessa situação, dá muito medo mesmo". (Mateus)

“Eu tive muito medo na minha primeira visita lá na UTI. Me senti impotente diante de minha filha tão pequena cheia de fios e tubos,e eu sem receber informação. Sai de lá muito triste, angustiado e com muito medo que ela não saísse Dalí “ (João).

O prematuro internado na UTIN será privado de tudo Que um bebê a termo recebe ao nascer no Que se refere aos cuidados parentais. No lugar de cuidados maternos e paternos, o recém nascido prematuro, na maioria das vezes, necessita ser afastado dos pais e familiares para receber intervenções e procedimentos invasivos necessários a sua sobrevivência na UTIN ${ }^{(13)}$.

A UTIN é um cenário familiar para os profissionais de saúde Que ali atuam, porém, para os pais, pode parecer um ambiente hostil e pouco acolhedor desencadeando nos mesmos sentimentos e reações desagradáveis como tristeza, ansiedade, angústia e principalmente medo.

O medo, expresso nas falas dos depoentes está associado à não sobrevivência do filho. A morte é um fato temido por todo ser humano, em especial pelos pais Que comumente não aceitam Que seus filhos morram antes deles, pois estariam alterando a ordem natural do ciclo da vida. A UTIN é uma unidade complexa onde sobreviver e morrer está no imaginário das famílias. Esse setor, apesar de ser necessário ao recém nascido prematuro dada as suas peculiaridades, leva os pais a um estado de insegurança, acirrada pela definição social atribuída a esse ambiente. Sendo um setor no Qual o paciente vai em um estado crítico de saúde, passa a representar para os pais algo adverso ao esperado durante a gravidez, isto é um parto a termo e sem intercorrências.

O fato dos entrevistados sentirem também tristeza e preocupação torna-se relevante Quando consideramos Que o parto prematuro, representa um momento no Qual os pais são levados a vivenciar insegurança, fragilidade e solidão diante do contexto da UTIN e de seus equipamentos. Essa realidade exige dos mesmos um processo de amadurecimento, de modo Que a UTI como estranho ás suas expectativas seja considerada natural no seu dia-a-dia.

Para os pais é difícil verem os seus filhos ligados a fios e tubos cercados de cuidados e aparelhos, como demonstram algumas falas dos entrevistados. A insegurança e o medo referidos por eles podem estar atrelados ao desconhecimento acerca da prematuridade e da unidade de internamento onde se encontra. Sentimentos semelhantes foram também apontados por mães cujos filhos encontravam-se na mesma condição. Nesse estudo as mães revelaram Que são vários os significados vivenciados por elas Quais sejam - angústia, ansiedade, preocupação, alegria, medo do desconhecido e das diversas situações experienciadas, dentre elas, separação da família durante a hospitalização, mudança de hábitos do dia a dia, separação do companheiro, dentre outros ${ }^{(14,15)}$.

Essa situação tende a ser atenuada com estratégias assistenciais voltadas para os pais de recém-nascidos prematuros necessitados de cuidados especiais. Os depoimentos denunciam também a falta de informações por parte dos profissionais Que atuam nessa unidade. A equipe que cuida do bebê prematuro deve ter como uma das 
suas atribuições acolher o pai e fornecer informações durante todas as etapas da hospitalização, dando explicações a cerca do estado de saúde de seus filhos, bem como da importância dos equipamentos utilizados na assistência dos mesmos. Esse fato foi constatado em outros momentos. Estudo realizado com homens Que estiveram presentes durante o nascimento aponta a falta de informações ao pai/companheiro e revela Que os mesmos guardam em si o desejo de ajudar as mulheres, mas não sabem o Que e como fazer. Da mesma forma acontece no puerpério ${ }^{(9,16)}$.

A ausência de informações perpassa não só a prematuridade mas também outras etapas do processo reprodutivo, denotando a necessidade de uma avaliação dispensada à família, em particular ao homem enquanto pai e companheiro no processo do nascimento, em Qualquer Que seja o contexto.

A permanecia dos pais junto ao filho hospitalizado é um direito garantido pelo estatuto da criança e do adolescente $e^{(17)}$, porém em muitas localidades esse direito ainda não está sendo cumprido. Dessa forma a presença paterna fica limitada aos horários das visitas hospitalares e por vezes, são vistos como intrusos por alguns profissionais prestadores de cuidados aos recém nascidos hospitalizados na UTIN.

Reconhecendo essa situação, o Ministério da Saúde lançou diretrizes Que norteiam a equipe para facilitar a formação dos vínculos afetivos e duradouros. Dentre elas destacam-se: o livre acesso dos pais à unidade de terapia neonatal; o direito do pai ter um profissional para fornecer QualQuer informação sobre o seu filho internado, sobretudo, na primeira visita; estimular os pais a tocar e acariciar os seus filhos; tornar o ambiente da UTIN acolhedor aos mesmos; permitir Que participem dos cuidados de seus bebês; escutar atentamente o Que têm a dizer; esclarecer as dúvidas Que possam ter, dentre outros ${ }^{(13)}$.

Todavia, os profissionais Que atuam em UTI têm a característica de se voltar para a técnica, para a doença e para o físico com vistas à sobrevivência do paciente. Entretanto, os trabalhadores de saúde Que ali atuam devem ter capacidade técnica e dispor de bom relacionamento interpessoal ${ }^{(18)}$.

Tratando-se dos participantes deste estudo somos levadas a admitir Que não houve interação entre a equipe neonatal e os pais, agravando o medo, a angústia e a incerteza Quanto as condições do prematuro. Isto revela Que a política de humanização nas UTINs das instituições nas Quais o estudo foi desenvolvido, não é posta em prática. Logo, é preciso repensar os cuidados desempenhados pelos profissionais de modo Que o prematuro seja visto como um ser humano advindo de um contexto familiar no Qual, na maioria das vezes, os pais desconhecem a necessidade de todo "aparato" para uma assistência especializada. Os familiares, em particular os pais, precisam ser esclarecidos na perspectiva de estabelecer vínculo afetivo com o filho como também ajudar a companheira e juntos superarem esse momento difícil para ambos.

De modo geral, a UTIN é traumatizante, pois na maioria das vezes a admissão do paciente ocorre de forma não planejada gerando neles e nos familiares oscilações psicológicas expressas por diversas emoções como: medo, tristeza e desespero por sentirem-se impotentes diante da situação vivenciada. O internamento de um ente Querido representa para os membros da família o medo da morte, sobrecarga na vida pessoal e isolamento ${ }^{(19)}$.

Nessa discussão vale acrescentar que a tecnologia utilizada, os aparelhos ultra-modernos desencadeiam medo e insegurança nos genitores mas esses sentimentos se amenizam à medida Que recebem orientações e confiam na equipe que cuida de seus filhos ${ }^{(20)}$.

Além dos sentimentos não favoráveis ao bem estar paterno por ocasião da prematuridade e da UTIN, os participantes referiram ter fé em Deus, confiança na equipe responsável pelos cuidados prestados ao filho prematuro e a esperança de superação do estado crítico em Que se encontravam.

"Eu me sinto alegre por ele estar aqui, melhorando a cada momento, a cada dia. Agora é só alegria. Agradecer muito a Deus. Eu estou muito feliz". (Lucas)

"Eu tenho muita fé em Deus que tudo vai dar certo, tenho também confiança nos profissionais que cuidam dele, apesar de não conversarem muito comigo. Mais a gente percebe Que eles sabem muito, cuidam bem deles, eles são muito profissionais". (Pedro)

"Agora eu estou muito feliz, cheio de esperança, a minha filha está melhorando a cada dia, está até pesando $1200 \mathrm{~g}$. Tenho Que agradecer muito, primeiramente a Deus e depois os profissionais que cuidaram dela. O susto e o medo estão passando. Agora é só alegria, pois tenho que cuidar de minha mulher e de minha filha". (Daniel)

Os depoimentos revelam Que após o primeiro impacto do internamento do filho na UTIN e observando a evolução das condições de sua saúde, os pais passam a reconhecer a necessidade de permanência do prematuro naquele setor. Além disso, entendem Que os profissionais de saúde possuem capacidade técnica para desempenho de suas funções. Dessa forma, novos sentimentos são aflorados como a fé, a alegria, confiança e esperança.

Nesse sentido, conforme estudo desenvolvido o sentimento de alegria ressaltado por pais, cujos filhos estavam internados em uma UTIN por prematuridade, decorre da confiança depositada na equipe Que ali atua ${ }^{(21)}$.

Consoantes as falas dos entrevistados mesmo com a ausência de informações, eles reconhecem a capacidade técnica da equipe Que trabalha na UTIN. Esse resultado corrobora com outras investigações nas Quais familiares de pacientes internados na UTI ressaltaram confiança, satisfação, agradecimento a Deus e aos profissionais. Além disso, acrescentaram solidão por falta de atenção e orientação, Quanto aos aspectos Que envolvem um setor temeroso.

Isto leva-nos a considerar Que o fato da UTIN representar para os pais um ambiente ameaçador e necessário à sobrevivência do filho encerra a dualidade de representações.

\section{CONSIDERAÇÕES FINAIS}

A representação da UTIN pauta-se nas definições dadas pelos pais Que se voltam para um ambiente ameaçador no Qual viver ou morrer apresenta-se como limite entre o hoje incerto e um amanhã nefasto. Nesse contexto, o pai em um processo de objetivação e ancoragem muda suas concepções diante do espaço de tempo representado pelo início do internamento. Novos sentimentos surgem e no decorrer do tempo, as dificuldades de aceitação vão sendo 
paulatinamente superadas mediante a melhoria das condições de saúde do prematuro. Nesse sentido, a UTIN passa a representar um ambiente assustador, mas necessário aos cuidados especializados requeridos pelas condições do recém nascido prematuro.

Retomando o assunto para a Questão de pesquisa, cabe-nos dizer Que o fato do pai ter um filho prematuro internado na UTI neonatal representa vivenciar emoções Que são traduzidas por medo, angústia, ansiedade, solidão, Que se entremeiam a fé, alegria e esperança.

Os resultados obtidos neste estudo revelam necessidade de se investigar outros aspectos Que envolvem o pai e o prematuro em condições de internamento.

\section{REFERÊNCIAS}

1. Ministério da Saúde (BR). Gestação de alto Risco: Manual técnico. $3^{\text {a }}$ ed. Brasília (DF): Ministério da Saúde; 2000.

2. Tougt SC, Newburn-Cook CV, White DE, Frase-Lee NI, Faber AH, Frick C, Svenson LW, et al. Do maternal characteristics and past pregnancy experiences predict pretem delivery among women aged 20 to 34? I Obstet Gynecol Can 2003: 25(8): 656-66.

3. Oliveira CA, Lins CP, Sá RAM, Netto HC, Bornia RG, Silva NR, Junior AJ. Síndromes hipertensivas na gestação e repercussões perinatais. Rev Bras Saúde Mater Infant 2006; 6(1): 93-8.

4. Organização Mundial de Saúde. Avalible from: http:// www.redesaude.org.br

5. Organização Panamericana da Saúde. Atenção integrada às doenças prevalentes na infância (AIDPI): manual para capacitação de profissionais da atenção primária. Fortaleza: Escola de Saúde Pública do Ceará; 2005.

6. Secretaria do Estado do Rio Grande do Norte. Coordenadoria de promoção á Saúde. Natal: Imprensa Oficial; 2007.

7. Avery GB. Neonatologia. Rio de Janeiro: MEDSI; 1999.

8. Coutinho HRB, Morsch DS. A paternidade em cuidados intensivos neonatais. Rev SBPH 2006; 9(1): 55-69.

9. Carvalho JBL. Nascimento de um filho: o significado para o pai [dissertação]. Natal: Departamento de Enfermagem de Natal, Universidade Federal do Rio Grande do Norte; 2005.

10. Ministério da Saúde (BR). Conselho Nacional de Saúde. Comissão Nacional de Ética. Resolução 196/96. Diretrizes e normas reguladoras de pesQuisa envolvendo seres humanos: Brasília: Ministério da Saúde; 1996.

11. Bardin L. Analise de conteúdo. Lisboa: Edições 70; 2000.

12. Moscovici S. A representação social da psicanálise. Rio de laneiro. Zahar; 1978
13. Ministério da Saúde (BR). Secretaria de Políticas de Saúde. Área Técnica de Saúde da Criança. Atenção humanizada ao recém nascido de baixo peso - método mãe canguru. Brasília: Ministério da Saúde; 2001 .

14. Vasconcelos MGL, Leite AM, Scochi CG. Significados atribuídos à vivencia materna como acompanhante do recém nascido prétermo e de baixo peso. Rev Bras Saúde Mater Infant 2006; 6(1): 47-57.

15. Ditts ES, Mota IAC, Sena RR. O cotidiano no alojamento conjunto, das mães de crianças internadas em uma UTI de Terapia Intensiva e Neonatal. Rev Bras Saúde Mater Infant 2008; 8(1): 75-81.

16. Oliveira EMF. Vivência do homem no puerpério [dissertação] Natal: Departamento de Enfermagem Universidade Federal do Rio Grande do Norte; 2007.

17. Senado Federal (BR). Lei Federal n. 8069. Dispõe sobre o Estatuto da Criança e do Adolescente. Diário Oficial da União 1990 jul 13

18. Albuquerque NMG. Vivencia do enfermeiro no cuidado humano na unidade de terapia intensiva adulto [dissertação]. Natal: Departamento de Enfermagem de Natal, Universidade Federal do Rio Grande do Norte; 2007.

19. Comassetto I. Vivencias familiares do paciente internado em uma unidade de terapia intensiva: estudo fenomenológico [dissertação]. Natal: Departamento de Enfermagem de Natal, Universidade Federal do Rio Grande do Norte; 2007.

20. Mittag, BF, Wall MI. Pais com filhos internados na UTI neonatal - sentimentos e percepções. Rev Fam Saúde Desenv 2004; 6 (2): 134-45

2 I. Cardoso MVLML, Souto KC, Oliveira MMCO. Compreendendo a experiência de ser pai de recém-nascido prematuro internado na unidade neonatal. Rev RENE 2006; 7(3): 49-55. 